Arq. Bras. Med. Vet. Zootec., v.67, n.2, p.591-599, 2015

\title{
Mananoligossacarídeo e B-glucano em dietas de leitões desmamados
}

\author{
[Mannan Oligosaccharides and $\beta$-glucan in diets for weaned piglets] \\ U.V. Luna ${ }^{1}$, J.G. Caramori Júnior ${ }^{2}$, G.S.S. Corrêa $a^{2}$, C. Kiefer ${ }^{3}$, M.A. Souza ${ }^{2}$, F.M. Vieites ${ }^{2}$, \\ R.A.S. Cruz ${ }^{2}$, S.D. Assis ${ }^{1}$ \\ ${ }^{1}$ Aluno de pós-graduação - Universidade Federal de Mato Grosso - UFMT - Cuiabá, MT \\ ${ }^{2}$ Universidade Federal de Mato Grosso - UFMT - Cuiabá, MT \\ ${ }^{3}$ Universidade Federal de Mato Grosso do Sul - UFMS - Campo Grande, MS \\ RESUMO
}

\begin{abstract}
Avaliou-se o efeito da suplementação de mananoligossacarídeo, ß-glucano e antibiótico em dietas de leitões machos castrados, durante a fase de creche (21 aos 54 dias de idade), sobre o desempenho, características morfo-histológicas da mucosa intestinal e ocorrência de diarreia. Foram utilizados 368 leitões de mesma linhagem, distribuídos em delineamento inteiramente ao acaso, com quatro tratamentos (1: 330g de mananoligossacarídeo t/ração (oriundos do núcleo), 2: 1.830g de mananoligossacarídeo t/ração (330g oriundos do núcleo + $1.550 \mathrm{~g}$ da suplementação), 3: 330g de mananoligossacarídeo (oriundos do núcleo) + 500g de ßglucano t/ração e 4: $330 \mathrm{~g}$ de mananoligossacarídeo (oriundos do núcleo) + 250g de Colistina t/ração) e quatro repetições com 23 animais por unidade experimental. O desempenho foi avaliado pelo ganho de peso, consumo de ração e conversão alimentar. As características morfo-histológicas da mucosa intestinal estudadas foram altura de vilosidade, profundidade das criptas intestinais, perímetro de vilosidade e a relação altura de vilosidade:profundidade de cripta do duodeno, jejuno e íleo. A ocorrência de diarreia foi observada diariamente pela avaliação de escore fecal. A suplementação de mananoligossacarídeo, $\beta$-glucano e antibiótico na dieta de leitões machos castrados, na fase de creche, não influenciaram o desempenho e a ocorrência de diarreia. Maior altura de vilosidade e maior profundidade de criptas no duodeno e íleo foram verificadas nos animais suplementados com ß-glucano. No jejuno foi observado maior perímetro de vilosidade nos animais suplementados com ß-glucano e nos animais que não receberam suplemento adicional na dieta.
\end{abstract}

Palavras-chave: aditivo, desmame, diarreia, microingrediente nutricional, morfometria intestinal

\begin{abstract}
The aim of this study was to evaluate the effect of supplementation with mannan oligosaccharides, $\beta$-glucan and antibiotic in diets for castrated male piglets during the nursery phase (21 to 54 days of age) on performance, morpho-histological characteristics of the intestinal mucosa and occurrence of diarrhea. A total of 368 piglets of the same strain, distributed in a completely randomized design with four treatments $(1-330 \mathrm{~g}$ mannan oligosaccharides/t of diet (derived of nucleus); 2 - 1,830 g mannan oligosaccharides/t of diet (330g derived of nucleus $+1550 \mathrm{~g}$ of supplementation); 3 - $330 \mathrm{~g}$ mannan oligosaccharides (derived of nucleus) + $500 \mathrm{~g} \beta$-glucan/t of diet; and 4 - 330g mannan oligosaccharides (derived of nucleus) $+250 \mathrm{~g}$ colistin/t of diet) and four replications with 23 animals per experimental unit. Performance was assessed through weight gain, feed intake and feed conversion. The morpho-histological characteristics of the intestinal mucosa studied were villus height, intestinal crypt depth, villus circumference and villus height:crypt depth of duodenum, jejunum and ileum ratio. The occurrence of diarrhea was observed daily by the evaluation of fecal score. Supplementation of mannan oligosaccharides, $\beta$-glucan and antibiotic in the diet of castrated male piglets in the nursery phase did not affect performance and occurrence of diarrhea. Greater villus height and crypt depth in the duodenum and ileum were verified in the animals supplemented with $\beta$-glucan. In the jejunum, greater villus circumference was observed in the animals supplemented with $\beta$-glucan and in the animals that did not receive additional supplemented diet.
\end{abstract}

Keywords: additive, diarrhea, intestinal morphology, nutritional micro-ingredient, weaning

Recebido em 19 de agosto de 2013

Aceito em 20 de outubro de 2014

E-mail: uandersonluna@hotmail.com 


\section{INTRODUÇÃO}

No período pós-desmama na produção de suínos, ocorrem mudanças de alimento, na forma física da dieta, na variação na proporção dos nutrientes e fatores estressantes que ocasionam mudanças funcionais e estruturais dos órgãos que compõem o sistema digestório. Em resposta a essas modificações, ocorre redução no desempenho, normalmente associada a alterações histológicas e bioquímicas no intestino delgado, como atrofia dos vilos e hiperplasia das criptas, que diminuem a capacidade de digerir e absorver nutrientes da dieta (Pluske et al. 1997; Cristani, 2008), além de grandes modificações microbiológicas.

A utilização de doses subterapêuticas de antibióticos na dieta, como moduladores de desempenho, previne ou reduz a população de micro-organismos patogênicos no trato gastrointestinal (TGI), e melhora a taxa de crescimento e a eficiência alimentar dos animais (Fedalto et al., 2002). Entretanto, os antibióticos estão sendo restringidos por vários países, pois há uma preocupação de que a utilização de doses subterapêuticas pode provocar resistência bacteriana, nos seres humanos, através do consumo de carnes e subprodutos de origem animal produzidos com esses moduladores de desempenho (Barros et al., 2008).

Os prebióticos vêm como alternativa aos antibióticos, pois não são digeríveis na parte superior do TGI dos animais, constituindo-se em um substrato seletivo para um limitado número de bactérias comensais benéficas do trato digestório, as quais têm crescimento no metabolismo estimulado. Os mananoligossacarídeos (MOS) e os $\beta$-glucanos são exemplos de prebióticos extraídos da parede celular de leveduras que têm por finalidade ajudar na manutenção da eficiência digestiva, integridade do epitélio intestinal, aumentando assim a absorção de nutrientes, estimulando também o sistema imune (Budiño et al. 2010).

Assim, o objetivo do trabalho foi avaliar a suplementação de prebióticos (Mananoligossacarídeo e ß-glucano) e antibiótico (Colistina) em dietas de leitões machos castrados, na fase de creche ( 21 aos 54 dias de idade), em granja comercial, onde os animais recebiam dietas contendo núcleo comercial, sobre o desempenho, ocorrência de diarreia e características morfohistológicas da mucosa intestinal.

\section{MATERIAL E MÉTODOS}

Foram utilizados 368 leitões machos de linhagem comercial, desmamados aos 21 dias de idade, com peso médio de $6,9 \mathrm{~kg}$, distribuídos em delineamento inteiramente ao acaso, com quatro tratamentos (1: 330g de mananoligossacarídeo t/ração (oriundos do núcleo), 2: $1.830 \mathrm{~g}$ de mananoligossacarídeo t/ração $(330 \mathrm{~g}$ oriundos do núcleo $+1550 \mathrm{~g}$ da suplementação), 3: 330g de mananoligossacarídeo (oriundos do núcleo) + 500g de B-glucano t/ração e 4: $330 \mathrm{~g}$ de mananoligossacarídeo (oriundos do núcleo) $+250 \mathrm{~g}$ de Colistina t/ração) e quatro repetições com 23 animais por unidade experimental.

As dietas experimentais (Tab. 1) foram isocalóricas e isoproteicas, formuladas com adaptações para $\mathrm{o}$ clima da região, à base de milho, farelo de soja e açúcar, suplementadas com minerais e vitaminas, para atender os níveis de exigências nutricionais de suínos com alto potencial genético, semelhantemente às tabelas de composições de alimentos e exigências de Rostagno et al. (2011), para as fases e idades: Pré I: $21^{\circ}$ ao $27^{\circ}$ dia de idade; Pré II: $28^{\circ}$ ao $34^{\circ}$ dia de idade; Inicial I: $35^{\circ}$ ao $44^{\circ}$ dia de idade; Inicial II: $45^{\circ}$ ao $54^{\circ}$ dia de idade. Os suplementos (prebióticos e o antibiótico) foram adicionados nas dietas em substituição ao inerte. A ração e a água foram fornecidas ad libitum.

Os animais foram pesados no início e ao final de cada período experimental $\left(27^{\circ}, 34^{\circ}, 44^{\circ}\right.$ e $54^{\circ}$ dia de idade), bem como as sobras de rações, calculando-se o peso corporal, o ganho de peso (GP), o consumo (CR) e conversão alimentar (CA).

A ocorrência de diarreia foi avaliada através das observações dos escores fecais dos leitões uma vez ao dia (às $07 \mathrm{~h} 30 \mathrm{~min}$ ). Os escores utilizados foram: fezes normais (1), fezes pastosas (2) e fezes diarreicas (3), conforme classificação proposta por Sobestiansky et al. (1998). A presença de fezes diarreicas no piso da baia foi utilizada como indicativo de ocorrência de diarreia. Os leitões que apresentaram sinais de diarreia não foram medicados durante o experimento. Ao final do experimento, foi calculada a ocorrência de diarreia por unidade experimental $(\%)$ entre o início e o fim do experimento. 
Tabela 1. Composição percentual das dietas experimentais em cada fase

\begin{tabular}{|c|c|c|c|c|}
\hline Ingredientes (\%) & Pré I & Pré II & Inicial I & Inicial II \\
\hline Milho & 25,650 & 36,050 & 47,100 & 57,785 \\
\hline Farelo de soja $(45 \%)$ & 9,700 & 18,400 & 22,450 & 28,500 \\
\hline Óleo de soja & 2,000 & 2,900 & 2,800 & 2,000 \\
\hline Farinha de Carne ( $45 \%)$ & 0,000 & 0,000 & 0,000 & 3,500 \\
\hline Açúcar Cristal & 2,500 & 2,500 & 2,500 & 5,000 \\
\hline DL-Metionina (99\%) & 0,000 & 0,000 & 0,000 & 0,148 \\
\hline L-Lisina $(78 \%)$ & 0,000 & 0,000 & 0,000 & 0,302 \\
\hline Treonina $(98 \%)$ & 0,000 & 0,000 & 0,000 & 0,115 \\
\hline $\mathrm{Nc} \mathrm{Sui}{ }^{1}$ & 60,000 & 40,000 & 25,000 & 2,500 \\
\hline Inerte (Areia lavada) & 0,150 & 0,150 & 0,150 & 0,150 \\
\hline Total $(\%)$ & 100,000 & 100,000 & 100,000 & 100,000 \\
\hline \multicolumn{5}{|c|}{ Composições calculadas } \\
\hline Energia Metabolizável (Kcal/Kg) & 3,450 & 3,448 & 3,451 & 3,400 \\
\hline Proteína Bruta (\%) & 18,575 & 19,743 & 19,312 & 20,173 \\
\hline Gordura Bruta (\%) & 5,603 & 6,287 & 6,527 & 5,232 \\
\hline Fibra Bruta $(\%)$ & 1,405 & 1,922 & 2,235 & 2,668 \\
\hline Cinza $(\%)$ & 6,219 & 6,279 & 6,107 & 4,810 \\
\hline Cálcio (\%) & 0,654 & 0,672 & 0,704 & 0,740 \\
\hline Fósforo disponível (\%) & 0,218 & 0,226 & 0,220 & 0,173 \\
\hline Lisina Total $(\%)$ & 1,561 & 1,446 & 1,319 & 1,271 \\
\hline \multicolumn{5}{|c|}{ 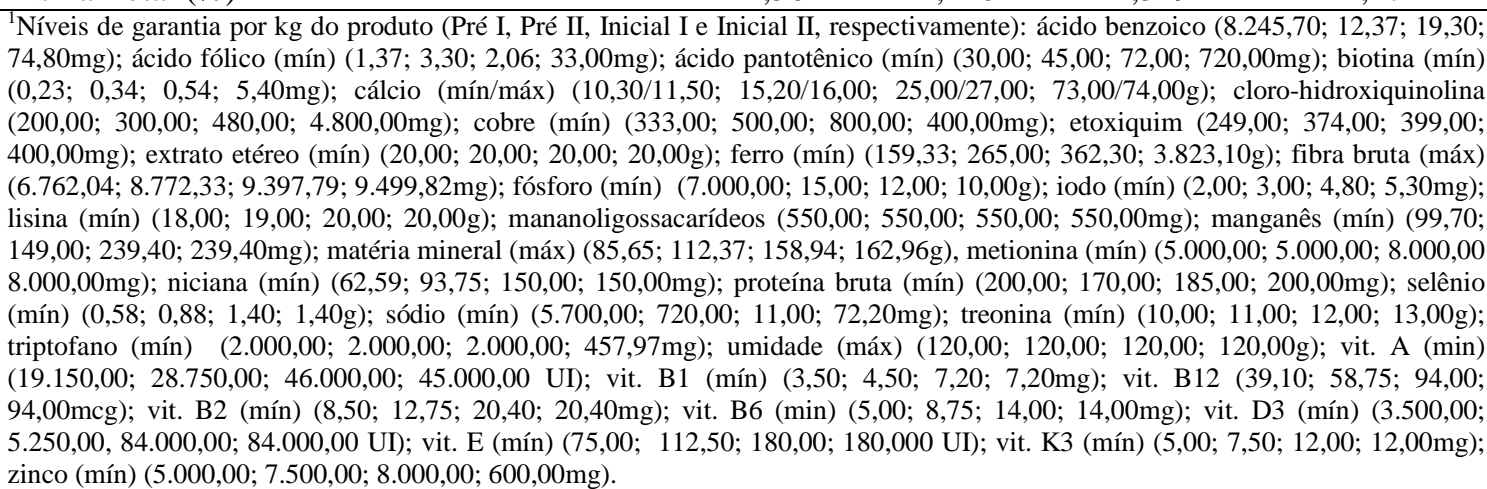 } \\
\hline
\end{tabular}

Para avaliação morfo-histológica, utilizou-se o intestino delgado de um animal por repetição, os quais foram eutanasiados e necropsiados aos 54 dias de idade. Foram coletados dois fragmentos (A e B) de $5 \mathrm{~cm}$ por região (duodeno, jejuno e íleo) em intervalos de $15 \mathrm{~cm}$ entre as mesmas. As amostras foram acondicionadas em frascos contendo formol a $10 \%$ para fixação, seguindo metodologia de Nabuurs et al. (1993).

As amostras foram levadas ao Laboratório de Patologia Veterinária da Universidade Federal de Mato Grosso, lavadas em álcool $70 \%$ para a retirada do fixador, posteriormente desidratadas em série crescente de álcoois $(80 \%, 85 \%, 90 \%$ e $95 \%$ e duas soluções a $96 \%$ ), diafanizadas em xilol e incluídas em parafina. Após a microtomia semisseriada a uma espessura de $5 \mu \mathrm{m}$, os fragmentos A e B, correspondendo a 2 cortes histológicos de uma mesma região de cada segmento (duodeno, jejuno e íleo), foram colocados em uma mesma lâmina histológica, corados pela hematoxilina e eosina (Behmer et al. 1976), e observados em microscópio óptico Axio Imager A2 da ZEISS.

Para estudo morfométrico da altura da vilosidade, do perímetro e das profundidades das criptas intestinais em micra $(\mu \mathrm{m})$, as amostras foram digitalizadas e mensuradas utilizando-se $o$ software analisador de imagens Axio Vision 4.8.2.0 da ZEISS acoplado a um microscópio binocular Axio Imager A2 da ZEISS. Em um total de 96 lâminas (4 tratamentos x 4 repetições x 1 animal x 3 segmentos x 2 cortes região), foram efetuadas 30 leituras/lâmina (10 leituras para altura de vilo, 10 para perímetro de vilo e 10 
para profundidade de cripta), perfazendo um total de 2.880 leituras de microscopia de luz (720 por tratamento). As medidas de altura de vilosidade (AV) foram tomadas a partir da região basal, que coincide com a porção superior das criptas, percorrendo-a longitudinalmente até seu ápice, e a profundidade de criptas (PC), da sua base até a região de transição cripta-vilosidade, e, para o perímetro (PV), contornaram-se as reentrâncias presentes no vilo. A partir das medidas de AV e PC, calculou-se a relação AV/PC para cada amostra.

Os dados foram submetidos à analise estatística utilizando-se o programa estatístico SAEG (Sistema de Análises Estatísticas e Genéticas) versão 9.1 (Sistema..., 2007) por meio dos procedimentos para análises de variância (ANOVA). Quando significativo, utilizou-se o teste Student Newman Keuls (SNK) no nível de 5\% de probabilidade.

\section{RESULTADOS E DISCUSSÃO}

Os diferentes tratamentos não influenciaram o ganho de peso, consumo de ração e a conversão alimentar do $21^{\circ}$ ao $27^{\circ}, 21^{\circ}$ ao $34^{\circ}, 21^{\circ}$ ao $44^{\circ}$ e $21^{\circ}$ ao $54^{\circ}$ dia de idade (Tab. 2).

Resultados semelhantes foram encontrados por Sanches et al. (2006), ao estudarem 150g de probiótico Bacillus subtillis/ton de ração, $1.000 \mathrm{~g}$ de prebiótico MOS/ton de ração, simbiótico $=(150 \mathrm{~g}$ de probiótico + $1.000 \mathrm{~g}$ de prebiótico) e $60 \mathrm{~g}$ antibiótico Olaquindox/ton de ração sobre o desempenho de leitões desmamados. E também por Hahn et al. (2006), ao utilizarem diferentes níveis de B-glucano (0, 0,01, 0,02, 0,03, e $0,04 \%)$ e antibiótico (Apramicina) na deita de leitões, que não encontraram efeito significativo para o ganho de peso, consumo e conversão alimentar.

Tabela 2. Médias de ganho de peso (GP), consumo de ração (CR), conversão alimentar (CA) e coeficiente de variação $(\mathrm{CV})$ de leitões machos castrados de acordo com os tratamentos experimentais

\begin{tabular}{|c|c|c|c|c|c|}
\hline & TRAT $1 *$ & TRAT 2 & TRAT 3 & TRAT 4 & $\mathrm{CV} \%$ \\
\hline \multicolumn{6}{|c|}{21 - 27 dias de idade } \\
\hline Peso 27 dias (kg) & $8,24 \mathrm{~A}$ & $8,38 \mathrm{~A}$ & $8,42 \mathrm{~A}$ & $8,31 \mathrm{~A}$ & 1,35 \\
\hline GP (kg) & $1,33 \mathrm{~A}$ & $1,51 \mathrm{~A}$ & $1,50 \mathrm{~A}$ & $1,41 \mathrm{~A}$ & 9,70 \\
\hline $\mathrm{CR}(\mathrm{kg})$ & $1,56 \mathrm{~A}$ & $1,69 \mathrm{~A}$ & $1,67 \mathrm{~A}$ & $1,55 \mathrm{~A}$ & 5,37 \\
\hline $\mathrm{CA}$ & $1,17 \mathrm{~A}$ & $1,12 \mathrm{~A}$ & $1,12 \mathrm{~A}$ & $1,10 \mathrm{~A}$ & 9,97 \\
\hline \multicolumn{6}{|c|}{21 - 34 dias de idade } \\
\hline Peso 34 dias (kg) & $10,93 \mathrm{~A}$ & $10,77 \mathrm{~A}$ & $11,07 \mathrm{~A}$ & $10,90 \mathrm{~A}$ & 2,82 \\
\hline GP (kg) & $4,02 \mathrm{~A}$ & $3,85 \mathrm{~A}$ & $4,15 \mathrm{~A}$ & $4,00 \mathrm{~A}$ & 7,24 \\
\hline CR (kg) & $4,54 \mathrm{~A}$ & $4,62 \mathrm{~A}$ & $4,71 \mathrm{~A}$ & $4,38 \mathrm{~A}$ & 5,32 \\
\hline $\mathrm{CA}$ & $1,13 \mathrm{~A}$ & $1,20 \mathrm{~A}$ & $1,13 \mathrm{~A}$ & $1,09 \mathrm{~A}$ & 8,64 \\
\hline \multicolumn{6}{|c|}{21 - 44 dias de idade } \\
\hline Peso 44 dias (kg) & $14,68 \mathrm{~A}$ & $15,17 \mathrm{~A}$ & $15,21 \mathrm{~A}$ & $14,81 \mathrm{~A}$ & 3,73 \\
\hline $\mathrm{GP}(\mathrm{kg})$ & $7,77 \mathrm{~A}$ & $8,25 \mathrm{~A}$ & $8,29 \mathrm{~A}$ & $7,91 \mathrm{~A}$ & 6,72 \\
\hline CR (kg) & $12,42 \mathrm{~A}$ & $12,93 \mathrm{~A}$ & $13,03 \mathrm{~A}$ & $11,75 \mathrm{~A}$ & 4,50 \\
\hline $\mathrm{CA}$ & $1,55 \mathrm{~A}$ & $1,51 \mathrm{~A}$ & $1,51 \mathrm{~A}$ & $1,43 \mathrm{~A}$ & 7,88 \\
\hline \multicolumn{6}{|c|}{21 - 54 dias de idade } \\
\hline Peso 54 dias $(\mathrm{kg})$ & $20,90 \mathrm{~A}$ & $20,55 \mathrm{~A}$ & $20,94 \mathrm{~A}$ & $19,50 \mathrm{~A}$ & 3,24 \\
\hline GP (kg) & $14,00 \mathrm{~A}$ & $13,63 \mathrm{~A}$ & $14,01 \mathrm{~A}$ & $12,60 \mathrm{~A}$ & 4,89 \\
\hline CR (kg) & $28,05 \mathrm{~A}$ & $28,57 \mathrm{~A}$ & $29,20 \mathrm{~A}$ & $26,92 \mathrm{~A}$ & 4,28 \\
\hline $\mathrm{CA}$ & $2,00 \mathrm{~A}$ & $2,09 \mathrm{~A}$ & $2,08 \mathrm{~A}$ & $2,13 \mathrm{~A}$ & 3,46 \\
\hline
\end{tabular}

Médias seguidas de mesma letra na linha não se diferem estatisticamente pelo teste SNK no nível de 5\% de probabilidade. *TRAT 1: $330 \mathrm{~g}$ de mananoligossacarídeo t/ração (oriundos do núcleo); TRAT 2: 1.830g de mananoligossacarídeo t/ração $(330 \mathrm{~g}$ oriundos do núcleo $+1.500 \mathrm{~g}$ da suplementação); TRAT $3: 330 \mathrm{~g}$ de mananoligossacarídeo (oriundos do núcleo) + 500g de B-glucano t/ração e TRAT 4: 330g de mananoligossacarídeo (oriundos do núcleo) $+250 \mathrm{~g}$ de Colistina t/ração.

Cabe ressaltar que, apesar de a suplementação do MOS e ß-glucano não ter influenciado nos resultados de desempenho em comparação aos demais tratamentos, observou-se que os microingredientes apresentaram um efeito expressivo como melhoradores de desempenho, proporcionando resultados semelhantes aos obtidos com os animais suplementados com 
antibióticos, o que já se pode considerar como grande benefício, em função das exigências estabelecidas pelos países importadores da carne suína livre de antibióticos. Em relação ao fato de os animais que receberam o tratamento sem nenhuma suplementação terem apresentado resultados de desempenho semelhantes aos obtidos com os animais suplementados com os microingredientes e com o antibiótico, isso pode ser explicado pela presença do MOS no núcleo comercial utilizado na elaboração das dietas, o que provavelmente contribuiu para os resultados encontrados.

Para a incidência de diarreia, não foi observado efeito dos diferentes tratamentos durante o período avaliado (Tab. 3).

Tabela 3. Incidência de diarreia medida em escore no período de 21 aos 54 dias de idade

\begin{tabular}{lcccc}
\hline Tratamentos & \multicolumn{5}{c}{ Escore Fecal \% } \\
\hline & 1 & 2 & 3 & Média \\
\hline TRAT 1* & 54,54 & 9,09 & 11,36 & $25,00 \mathrm{~A}$ \\
TRAT 2 & 67,42 & 12,89 & 18,94 & $33,08 \mathrm{~A}$ \\
TRAT 3 & 70,45 & 12,12 & 15,91 & $32,80 \mathrm{~A}$ \\
TRAT 4 & 68,18 & 15,15 & 16,61 & $33,33 \mathrm{~A}$ \\
\hline Média & $65,15 \mathrm{~A}$ & $12,31 \mathrm{~B}$ & $15,72 \mathrm{~B}$ & - \\
\hline
\end{tabular}

Médias seguidas de mesma letra maiúscula na linha e na coluna não diferem entre si estatisticamente pelo teste SNK, no nível de 5\% de probabilidade. *TRAT 1: $330 \mathrm{~g}$ de mananoligossacarídeo t/ração (oriundos do núcleo); TRAT 2: $1.830 \mathrm{~g}$ de mananoligossacarídeo t/ração (330g oriundos do núcleo + 1.500g da suplementação); TRAT 3: 330g de mananoligossacarídeo (oriundos do núcleo) + 500g de ß-glucano t/ração e TRAT 4: 330g de mananoligossacarídeo (oriundos do núcleo) $+250 \mathrm{~g}$ de Colistina t/ração.

Entretanto, durante o experimento, observou-se baixa incidência de diarreia, de forma que $65 \%$ das observações foram de casos não diarreicos, o que diferiu estatisticamente da média de observações (12,31 e 15,72\%) para os escores 2 e 3 , respectivamente.

Possivelmente, a ocorrência de diarreia nessa fase ocorre devido à imaturidade dos sistemas digestório e imunológico dos leitões, que não estão totalmente desenvolvidos para enfrentar os desafios pós-desmame. Assim, os leitões estão mais susceptíveis a distúrbios gastrintestinais e enfermidades oportunistas. A inibição da fixação e colonização de micro-organismos patógenos no TGI dos leitões recém-desmamados atua na prevenção de diarreias, uma vez que as diarreias pós-desmame são causadas pela colonização da superfície epitelial por patógenos, como a Escherichia coli enterotoxigênica, Salmonella typhimurium e Clostridium spp. (Stewart e Chesson, 1993).

Avaliando os efeitos de antimicrobianos $(50 \mathrm{~g}$ de bacitracina de zinco/t de ração $+50 \mathrm{~g}$ de olaquindo x ton/ração), 300g de prebiótico MOS ton/ração, $1.300 \mathrm{~g}$ do probióticos Bacillus subtilis e Bacillus lincheniformis/ton/ração e $50 \mathrm{~g}$ de extrato vegetal (alho, cravo, canela, pimenta, tomilho, cinamaldeído e eugenol/ton/ração),
Utiyama et al. (2006) não encontraram efeito positivo sobre a ocorrência de diarreia na fase de creche. Também Budiño et al. (2010), ao estudarem diferentes níveis de Frutoligossacarídeo $(0,0 ; 0,2 ; 0,4$ e 0,6$)$, não verificaram efeitos desses produtos sobre a incidência de diarreia.

Os mecanismos envolvidos que podem influenciar na diminuição de distúrbios gastrintestinais através do uso de microingredientes na dieta ainda não estão totalmente elucidados. Sabe-se que as substâncias prebióticas podem atuar nos sistemas imune e enzimático, por promoverem o crescimento das populações de bactérias benéficas Lactobacillus e Bifidobacterium; isso porque têm grande capacidade de produzir substâncias com propriedades imunoestimulatórias e interagir com o sistema imune em vários níveis, incluindo a produção de citocinas, a proliferação de células mononucleares, a fagocitose macrofágica, a eliminação e a indução de síntese de grandes quantidades de imunoglobulinas (Ig), em especial as 595IgA, IgM e IgG (Silva e Nörnberg, 2003).

A adequada proporção de micro-organismos benéficos presentes nas dietas ajuda na 
manutenção da integridade do epitélio intestinal ocasionada pela reduzida fixação de microorganismos patógenos (Kyriakis et al., 1999). As bacteriocinas, além de reduzirem a fixação, podem atuar como bactericidas para as enterobactérias (Chateu et al., 1993). A produção de ácidos (acético, propiônico, butírico e lático) pelas bactérias láticas pode inibir o crescimento de patógenos mediante a redução do $\mathrm{pH}$ intestinal, tornando o meio impróprio para a multiplicação dos patógenos, ou pelo efeito direto dos ácidos sobre as enterobactérias (Jin et al., 1997).

A inibição da fixação e colonização de microorganismos patógenos no TGI dos leitões recémdesmamados atua como medida profilática na prevenção de diarreias, uma vez que as diarreias pós-desmame são causadas pela colonização da superfície epitelial por patógenos, como a Escherichia coli enterotoxigênica, Salmonella typhimurium e Clostridium spp. (Stewart e Chesson, 1993).
Os resultados da literatura ainda são muito controversos em relação a essa variável e isso se deve a muitos fatores, como as diferenças encontradas nos tipos de probiótico e prebiótico utilizados, dosagem, condições sanitárias (desafio) e ambientais presentes na criação.

Nas análises morfo-histológicas do intestino delgado (Tab. 4), observaram-se maiores alturas de vilosidades (AV) e profundidade de criptas (PC) no duodeno e íleo dos animais que receberam a suplementação contendo ß-glucano. Entretanto, os animais que não receberam a suplementação apresentaram resultados intermediários para AV. No jejuno foi observada diferença apenas para a variável perímetro de vilosidades (PV), sendo maior nos animais que receberam a suplementação com ß-glucano e nos animais que não receberam o suplemento na dieta. Os animais que receberam a suplementação contendo antibiótico apresentaram resultados intermediários em relação aos demais tratamentos.

Tabela 4. Médias da altura $(\mu \mathrm{m})$ das vilosidades (AV), profundidade das criptas (PC), perímetro das vilosidades (PV) relação da altura da vilosidade/profundidade cripta (AV/PC) medidas no duodeno, jejuno e íleo dos leitões aos 33 dias pós-desmame

\begin{tabular}{|c|c|c|c|c|}
\hline \multicolumn{5}{|c|}{ Duodeno } \\
\hline Tratamento & AV & $\mathrm{PC}$ & PV & $\mathrm{AV} / \mathrm{PC}$ \\
\hline TRAT $1 *$ & $297,75 B$ & $682,62 B$ & $358,75 \mathrm{~A}$ & $0,88 \mathrm{~A}$ \\
\hline TRAT 2 & $260,25 B$ & $572,32 \mathrm{~B}$ & $352,64 \mathrm{~A}$ & $0,78 \mathrm{~A}$ \\
\hline TRAT 3 & $356,55 \mathrm{~A}$ & $801,84 \mathrm{~A}$ & $366,01 \mathrm{~A}$ & $0,98 \mathrm{~A}$ \\
\hline TRAT 4 & $310,01 \mathrm{~B}$ & $668,75 B$ & $353,32 \mathrm{~A}$ & $1,01 \mathrm{~A}$ \\
\hline $\mathrm{CV} \%$ & 14,20 & 14,92 & 16,90 & 27,00 \\
\hline \multicolumn{5}{|c|}{ Jejuno } \\
\hline Tratamento & $\mathrm{AV}$ & $\mathrm{PC}$ & $\mathrm{PV}$ & $\mathrm{AV} / \mathrm{PC}$ \\
\hline TRAT $1 *$ & $293,48 \mathrm{~A}$ & $633,74 \mathrm{~A}$ & $376,68 \mathrm{~A}$ & $0,81 \mathrm{~A}$ \\
\hline TRAT 2 & $327,61 \mathrm{~A}$ & $744,89 \mathrm{~A}$ & $300,59 B$ & $1,17 \mathrm{~A}$ \\
\hline TRAT 3 & 332,97A & $733,80 \mathrm{~A}$ & $364,83 \mathrm{~A}$ & $1,00 \mathrm{~A}$ \\
\hline TRAT 4 & $318,04 \mathrm{~A}$ & $707,61 \mathrm{~A}$ & $342,24 \mathrm{AB}$ & $0,97 \mathrm{~A}$ \\
\hline $\mathrm{CV} \%$ & 21,12 & 16,77 & 13,76 & 23,62 \\
\hline \multicolumn{5}{|c|}{ Íleo } \\
\hline Tratamento & $\mathrm{AV}$ & $\mathrm{PC}$ & $\mathrm{PV}$ & $\mathrm{AV} / \mathrm{PC}$ \\
\hline TRAT $1 *$ & $288,36 \mathrm{AB}$ & $625,73 B$ & $275,24 \mathrm{~A}$ & $1,10 \mathrm{~A}$ \\
\hline TRAT 2 & $274,86 \mathrm{~B}$ & $609,46 \mathrm{~B}$ & $353,60 \mathrm{~A}$ & $0,86 \mathrm{~A}$ \\
\hline TRAT 3 & $358,99 \mathrm{~A}$ & $802,11 \mathrm{~A}$ & $366,66 \mathrm{~A}$ & $1,06 \mathrm{~A}$ \\
\hline TRAT 4 & $289,15 \mathrm{~B}$ & $623,62 \mathrm{~B}$ & $331,28 \mathrm{~A}$ & $0,96 \mathrm{~A}$ \\
\hline $\mathrm{CV} \%$ & 17,62 & 18,01 & 20,01 & 24,58 \\
\hline
\end{tabular}

Médias seguidas de letras diferentes na coluna diferem estatisticamente entre si pelo teste SNK, no nível de 5\% de probabilidade. *TRAT 1: $330 \mathrm{~g}$ de mananoligossacarídeo t/ração (oriundos do núcleo); TRAT 2: 1.830g de mananoligossacarídeo t/ração $(330 \mathrm{~g}$ oriundos do núcleo $+1.500 \mathrm{~g}$ da suplementação); TRAT $3: 330 \mathrm{~g}$ de mananoligossacarídeo (oriundos do núcleo) + 500g de ß-glucano t/ração e TRAT 4: 330g de mananoligossacarídeo (oriundos do núcleo) $+250 \mathrm{~g}$ de Colistina t/ração. 
Os resultados podem indicar uma possível melhora quanto à integridade do epitélio intestinal nos segmentos estudados, proporcionada pelo mecanismo de ação do ßglucano, já que o mesmo apresenta um importante papel durante a fase de creche, pois, ao inibir a colonização de micro-organismos indesejáveis, como Escherichia coli e Salmonella ssp., no TGI, e dificultar a ação de metabólitos tóxicos que influenciam a fisiologia da mucosa, contribui positivamente para a saúde intestinal. Esse fato ocorre pela indução de imunoglobulinas, em especial as do tipo $\operatorname{IgA}$, que possuem atuação local, e as do tipo IgM e IgG, que atuam em nível sérico, promovendo benefícios às características morfo-histológicas intestinais avaliadas neste trabalho, provavelmente ocasionados pela maior taxa de renovação das células maduras do epitélio intestinal.

Para a variável perímetro de vilosidade, animais que não receberam nenhum tipo de suplementação adicional (apenas o presente no núcleo) apresentaram resultados semelhantes aos suplementados com o B-glucano. A ausência de diferenças entre os tratamentos pode estar relacionada com o prebiótico MOS presente no núcleo comercial do tratamento sem suplementação adicional. Com base nessa possível influência, esperava-se que os animais suplementados com MOS também tivessem apresentado resultados positivos para essa variável, porém isso não ocorreu, visto que esses animais apresentaram os menores valores de PV, o que pode estar associado à quantidade de administração do MOS na dieta, havendo necessidade de mais pesquisas sobre a quantidade de microingredientes a ser incluída na dieta de suínos, bem como o tempo de fornecimento destes, em especial para a categoria estudada neste trabalho.

A relação altura de vilosidade:profundidade de cripta (AV:PC) não apresentou diferenças entre os tratamentos. A AV:PC é um parâmetro importante de ser observado, uma vez que a mesma está diretamente relacionada com a maior capacidade de absorção de nutrientes, que pode ser afetada pela menor altura de vilosidades em decorrência do aumento na taxa de descamação epitelial resultante do incremento da profundidade da cripta, visando assegurar a adequada taxa de renovação celular e garantir a reposição das perdas de células da região apical das vilosidades (Araújo et al., 2006; Oetting et al., 2006). Dessa forma, pode-se inferir que, quanto maior a relação AV:PC, melhor a capacidade de absorção de nutrientes e menores são as perdas energéticas com a renovação celular.

Os resultados encontrados neste experimento são contrários aos relatos de Li et al. (1991) e Tucci (2003), que afirmaram ser benéfica a redução na PC, uma vez que está associada à menor taxa de descamação e, ainda, ao menor encurtamento da vilosidade.

A associação da menor e da maior AV e da maior PC observada no período pós-desmame, com a redução na atividade das enzimas intestinais ligadas aos enterócitos na região da borda em escova, foi amplamente estudada por Hampson (1986), Hampson, Kidder (1986) e Pluske et al. (1996); porém, provavelmente influenciada por fatores adversos, essa relação nem sempre tem obedecido à hipótese da associação citada, como observado neste estudo.

As pesquisas realizadas têm procurado associar a redução na altura das vilosidades e incremento na profundidade das criptas, após o desmame, com a redução na atividade específica das enzimas presentes na borda em escova dos enterócitos, nos dias seguintes ao desmame. Acredita-se que um aumento na taxa de proliferação celular nas criptas e na migração dos enterócitos para a base das vilosidades aumentariam o tamanho dos vilos, porém com número de enterócitos imaturos com pouca atividade digestiva e absortiva (Smith, 1984; Hampson, 1986; Pluske et al., 1996).

Essa explicação pode justificar o que provavelmente ocorreu neste experimento, quando se compara os dados de morfometria intestinal com os dados de desempenho. Esperava-se maior desempenho para os animais que apresentaram maiores alturas de vilosidade e maior perímetro de vilosidade, associando-se a isso a maior área de absorção dos nutrientes proporcionada pelas melhores características histológicas do intestino, porém isso não ocorreu.

$O$ fato de os animais suplementados com mananoligossacarídeo e $\beta$-glucano não terem apresentado diferenças significativas no 
desempenho, em comparação aos suplementados com antibiótico, demonstrou que é viável a utilização desses microingredientes para evitar a utilização de antibióticos, mantendo-se o mesmo padrão de desempenho animal e atendendo às exigências do mercado internacional.

\section{CONCLUSÃO}

A suplementação de mananoligossacarídeo, $\beta$ glucano e antibiótico na dieta de leitões machos castrados, na fase de creche, não influenciou o desempenho e a ocorrência de diarreia. Maior altura de vilosidade e maior profundidade de criptas no duodeno e íleo foram verificadas nos animais suplementados com ß-glucano. No jejuno foi observado maior perímetro de vilosidade nos animais suplementados com Bglucano e nos animais que não receberam suplemento adicional na dieta.

\section{REFERÊNCIAS}

ARAÚJO, L.F.; JUNQUEIRA, O.M.; LOPES, E.L. et al. Utilização da levedura desidratada (Saccharomyces cerevisiae) para leitões na fase inicial. Cienc. Rural., v.36, p.1576-1581, 2006.

BARROS, D.S.; CARAMORI JÚNIOR, J.G.; SOUZA, V.C. et al. Efeito da adição de probiótico e prebiótico sobre o ganho de peso, consumo de ração e ocorrência de diarreia em leitões na fase de aleitamento. Rev. Bras. Saúde Prod. Anim., v.9, p.469-479, 2008.

BEHMER, O.A.; TOLOSA, E.M.C.; FREITAS NETO, A.G. (Eds.). Manual de técnicas para histologia normal e patológica. São Paulo: Edart, 1976. 256p.

BUDIÑO, F.E.L.; CASTRO JÚNIOR, F.G.; OTSUK, I.P. Adição de Frutoligossacarídeo em dietas para leitões desmamados: desempenho, incidência de diarreia e metabolismo. Rev. Bras. Zootec., v.39, p.2187-2193, 2010.

CHATEU, N.; CASTELLANOS, I.; DESCHAMPS, A.M.; Distribution of pathogen inhibitioning the Lactobacillus isolates of a commercial probiotic consortium. J. Appl. Bacteriol., v.74, p.36-40, 1993.
CRISTANI, J. Acidificantes e probióticos na alimentação de leitões recém desmamados. 2008. 57f. Tese (Doutorado em Zootecnia) Faculdade de Ciências Agrárias e Veterinária, Universidade Estadual Paulista, Jaboticabal.

FEDALTO, L.M.; TKACZ, M.; ADER, L.P. Probióticos na alimentação de leitões do desmame aos 63 dias de idade. Arch. Vet. Sci., v.7, p.83-88, 2002.

HAHN, T.W.; LOHAKARE, J.D.; LEE, S.L. et al. Effects of supplementatation of â-glucans on growth performance, nutrient digestibility and immunity weanling pigs. J. Anim. Sci., v.84, p.1422-1428, 2006.

HAMPSON, D.J. Alterations in piglet small intestinal structure at weaning. Res. Vet. Sci., v.40, p.32-40, 1986.

HAMPSOM, D.J.; KIDDER, D.E. Influence of creep feeding and weaning on brusch border enzyme activities in the piglet small intestine. Res. Vet. Sci., v.40, p.24-31, 1986.

JIN, L.Z.; HO, Y.W.; ABDULLAH, N. et al. Probiotics in poultry: modes of action. World's Poultry Sci. J., v.53, p.351-363, 1997.

KYRIAKIS， S.C.; TSILOYIANNIS， V.K.; VLEMMAS, J. et al. The effect of probiotic LSP 122 on the control of post-weaning diarrhea syndrome of piglets. Res. Vet. Sci., v.67, p.223228, 1999.

LI, D.F.; NELSSEN, J.L.; REDDY, P.G. et al. Interrelationship between hypersensitivy to soybean proteins and growth performance in early weaned pigs. J. Anim. Sci., v.69, p.40624069, 1991.

NABUURS, M.J.; HOOGENDOORN, A.; VAN DER MOLEN, E.J. et al. Villus height and crypt depth in weaned and unweaned pigs, reared under various circumstances in the Netherlands. Res. Vet. Sci., v.55, p.78-84, 1993.

OETTING, L.L.; UTIYAMA, C.E.; GIANI, P.A. et al. Efeitos de extratos vegetais $\mathrm{e}$ antimicrobianos sobre a digestibilidade aparente, morfometria e histologia intestinal de leitões recém desmamados, Rev. Bras. Zootec., v.35, p.1389-1397, 2006. 
PLUSKE, J.R.; HAMPSON, D.J.; WILLIANS, J.H. Factors influencing the structure and function of the small intestine in the weaned pig: a review. Livest. Prod. Sci., v.51, p.215-236, 1997.

PLUSKE, J.I.; WILLIAMS, I.; AHERNE, F. Maintenance of villus height and crypt depth in piglets by providing continuous nutrition after weaning. J. Anim. Sci., v.62, p.131, 1996.

ROSTAGNO, H.S.; ALBINO, L.F.T.; DONZELE, J.L. et al. Tabelas brasileiras para aves e suínos: Composição de alimentos e exigências nutricionais. Viçosa, MG: UFV, 2011. 252p.

SISTEMAS de Análises Estatísticas e Genéticas - SAEG (Versão 9.1). Viçosa, MG: Universidade Federal de Viçosa, 2007.

SANCHES, A.L.; LIMA, J.A.F.; FIALHO, E.T. et al. Utilização de probiótico, prebiótico e simbiótico em rações de leitões ao desmame. Ciênc. Agrotec., v.30, p.774-777, 2006.

SILVA, L.P.; NÖRNBERG, J.L. Prebióticos na nutrição de não-ruminantes. Res. Vet. Sci., v.33, p.55-65, 2003.
SMITH, M.W. Effect of post-natal development and weaning upon the capacity of pig intestinal villi to transport alanine. J. Agric. Sci. Technol., v.102, p.625, 1984.

SOBESTIANSKY, J.; WENTS, I.; SILVEIRA, P.R.S.; SESTI, L.A.C. Suinocultura intensiva: produção, manejo e saúde do rebanho. Brasil: EMBRAPA, 1998. 388p.

STEWART, C.S.; CHESSON, A. Making sense of probiotics. Pig Vet. J., v.31, p.11-33, 1993.

TUCCI, F.M. Efeitos da adição de agentes tróficos na dieta de leitões desmamados sobre a renovação celular da mucosa intestinal, enzimas digestivas e desempenho. 2003. 57f. Tese (Doutorado em Zootecnia) - Faculdade de Ciências Agrárias e Veterinárias - Universidade Estadual Paulista, Jaboticabal.

UTIYAMA, C.E.; OETTING, L.L.; GIANI, P.A. et al. Efeitos de antimicrobianos, prebióticos, probióticos e extratos vegetais sobre a microbiota intestinal, a frequência de diarreia e o desempenho de leitões recém-desmamados. Rev. Bras. Zootec., v.35, p.2359-2367, 2006. 